\title{
Effect of Thermal Aging on the Properties of Insulating Paper
}

\author{
Mengzhao ZHU*, Yufeng CHEN, Chao GU, Wenbing ZHU \\ State Grid Shandong Electric Power Research Institute \\ No.2000, Wangyue Rd, shizhong district \\ Jinan, China \\ e-mail: xiaozhupost@163.com,yufengchensgcc@163.com,guch2000@163.com,18605316092@163.com
}

\author{
Xiaozhuang MA \\ Shandong University of Technology \\ No.266, Xincunxi Rd, Zhangdian district \\ Zibo, China \\ e-mail: Maxz@163.com
}

\author{
Xin WANG \\ Qilu University of Technology \\ No.3501, Daxue Rd, Changqing district \\ Jinan, China \\ e-mail: wangxin2709@163.com
}

\begin{abstract}
In order to improve the safety of power equipment, the influence of thermal aging on the performance of insulating paper used for transformers was investigated, the same type insulation paper with different basis weight was used to simulate the thermal aging process. The paper folding endurance, the tensile strength and the fiber polymerization degree (DP) of the insulation paper were measured before and after the thermal aging. The result showed that thermal aging has deteriorated the paper's properties, the DP was decreased. The retention rate of the paper folding endurance was about $10 \%$ of the base paper, and the retention rate of the tensile strength was about $70 \%$ of the base paper. Compared to the tensile strength, the connection between the fibers has a greater impact on the paper folding endurance of the insulating paper. Therefore, paper folding endurance was a more realistic and efficient method to characterize the thermal aging degree of the insulating paper.
\end{abstract}

Keywords-paper folding endurance; insulation paper; thermal aging

\section{INTRODUCTION}

With the rapid economic development in our country, the installed capacity of electric power generation has rapidly increased. As of June 2017, State Grid Corporation of China has sold the electricity more than 1.82 trillion $\mathrm{kWh}$ during this year, an increase of $6.9 \%^{[1]}$. The emergence of UHV transmission was effectively solved the problem of low transmission efficiency. As an important part of $\mathrm{HV}$ and UHV transmission network, the transformer's safety operation determined the operation of the whole transmission network, the transformer's safety play an important role in the development of the State Grid Corporation of China.

Oil-paper insulation structure with excellent insulation properties, better physical and mechanical properties was widely used in transformers. During the storage and the using process, the insulation paper was withstand thermal effects, mechanical effects and the external pressure, resulting the different aging degrees of paper insulation. The working temperature of the transformer was generally higher, the temperature of the wire winding was $80-140^{\circ} \mathrm{C}^{[2]}$. The high temperature lead to the open chain of the cellulose macromolecule, the DP was decreased. Thermal aging was extremely damage to the insulation paper performance, resulting in reduced insulation, which may eventually lead to insulation equipment malfunction ${ }^{[3-4]}$. The thermal aging of the insulation paper was irreversible, a detailed study about the aging characteristics of insulation paper contribute to a more clear understanding of the aging process of insulation paper, which can effectively prevent the occurrence of transmission network security incidents. The current evaluation index about the thermal aging degree of insulation paper was the tensile strength and DP. Many insulating paper still has a certain degree of tensile strength under the thermal aging, but the paper folding endurance was seriously decreased. Therefore the folding endurance selected as an indicator of aging evaluation of the insulating papers was more flexible. Therefore, this paper select the paper folding endurance was selected as an efficient and comprehensive evaluation method for evaluating the thermal aging degree of the insulating paper.

\section{EXPERIMENTAL}

The dispersion of insulating paper pulp was selected as the raw material, the paper was made according to the different paper basis weight. The insulating paper was immersed in the oil tank with 25 \# naphthenic mineral oil, the temperature of oil bath was set on $120^{\circ} \mathrm{C}, 150^{\circ} \mathrm{C}, 180^{\circ} \mathrm{C}$, the thermal aging of the insulating paper was accelerated under laboratory conditions, and the tensile strength, DP and paper folding endurance of the insulating paper was measured.

\section{CHARACTERIZATION}

(1) In accordance with GB/T24324-2009 using paper sheet former to make paper accordance to different paper basis weight.

(2) The tensile strength of the insulating paper was measured according to GB/T453-2002, \&1 was the tensile 
strength of the sample before thermal aging, $\& 2$ was the tensile strength of the sample after thermal aging, $\S$ was the tensile strength retention of the sample.

$$
\S=\frac{\&_{1}-\&_{2}}{\&_{1}}
$$

(3) The DP of the insulating paper was measured according to GB/T1548-2004.

(4) The paper folding endurance of the insulating paper was measured using shepard folding instrument according to $\mathrm{GB} / \mathrm{T} 457-1989$.

\section{RESUlTS AND Discussion}

\section{A. Effect of thermal aging temperature and time on the} tensile strength of insulating paper

Figure 1 showed the influence of time on the tensile strength of the insulating paper with a basis weight of 70 $\mathrm{g} / \mathrm{m} 2$.

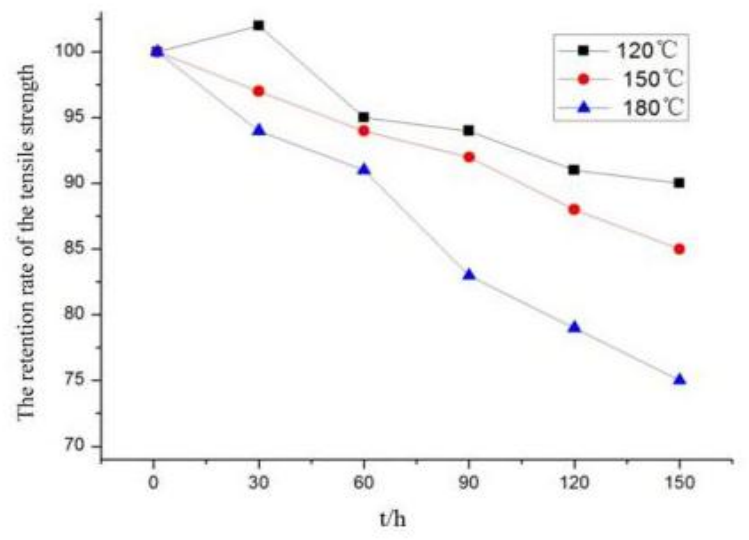

Figure 1. The influence of time on the tensile strength of the insulating paper.

From figure 1, the tensile strength of the insulating paper was increased firstly and then decreased. At the aging temperature of $150^{\circ} \mathrm{C}$ and $180^{\circ} \mathrm{C}$, the tensile strength of the insulating paper was decreased. The reason was that at the thermal aging temperature of $120^{\circ} \mathrm{C}$, during the earlier stage of the thermal aging, the moisture in the insulating paper was decreased, the insulating paper had a tendency of "shrinking", the distance between the fibers was decreased, the force between the adjoin fibers increased, and the tensile strength was increased. At the thermal aging temperature of $150^{\circ} \mathrm{C}$ and $180^{\circ} \mathrm{C}$, the insulating paper was exposed to high ambient temperature, the thermal aging destroyed the internal structure of the insulating paper, the tensile strength of the insulating paper was decreased.

\section{B. Effect of the thermal aging on the DP}

DP was an important parameter to characterize the degree of paper aging. Figure 2 showed the influence of the thermal aging on the DP, and the initial DP was set as 1000 . Figure 2 showed the DP was decreased with the thermal aging time increased. The higher the thermal aging temperature was, the faster the DP decreased. The reason was that under the thermal aging, the volatile components of the insulating paper was escaped, and the cellulose adsorbed water desorbed. With the increase of temperature, the glucose groups in the cellulose began to dehydrate, the (1 glucosidic bond ring breaking, the DP decreased, the thermal aging destroyed the structure of the insulating paper.

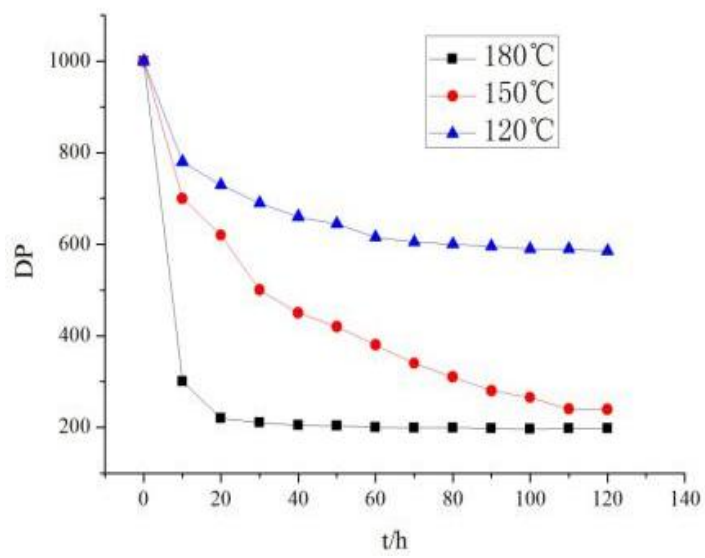

Figure 2. The influence of the thermal aging on the DP.

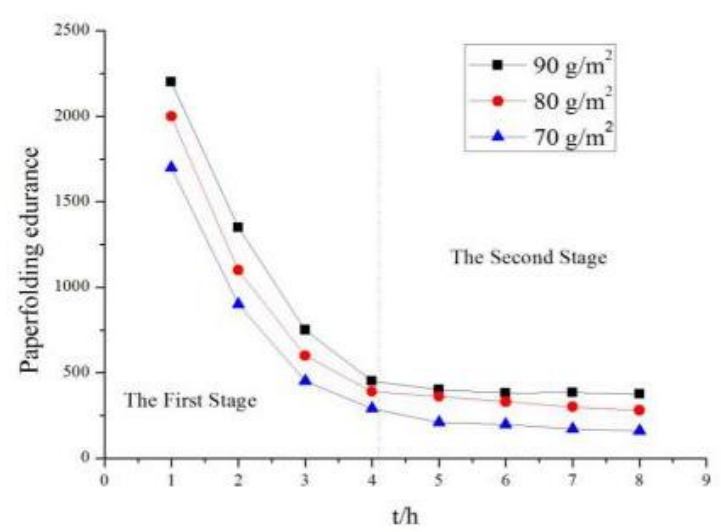

Figure 3. The influence of the thermal aging on the paper folding endurance.

\section{Effect of the thermal aging on the paper folding endurance}

Under the temperature of $180^{\circ} \mathrm{C}$, the insulating paper with basis weight of $70 \mathrm{~g} / \mathrm{m} 2,80 \mathrm{~g} / \mathrm{m} 2,90 \mathrm{~g} / \mathrm{m} 2$ was selected for thermal aging experiment. Figure 3 showed that the paper folding endurance was decreased rapidly with the thermal aging time expand. The larger the paper basis weight, the faster the paper folding endurance decreased. The paper folding endurance decrease was divided into two stages, in the first stage, the paper folding endurance dropped sharply, and the sample with paper basis weight of $90 \mathrm{~g} / \mathrm{m} 2$ dropped the fastest, the insulating paper with paper basis weight of $80 \mathrm{~g} / \mathrm{m} 2$ was secondly, and the insulating paper with paper basis weight of $70 \mathrm{~g} / \mathrm{m} 2$ was the last. In the second stage, the decrease of paper folding endurance of all insulating paper tended to be gentle, the paper folding endurance of the insulating paper with paper basis weight of 
$70 \mathrm{~g} / \mathrm{m} 2$ was the lowest. The reason was that under the effect of thermal aging, the fiber structure of the insulating paper was destroyed, and the insulating paper was easily damaged under the force of external bending. As the paper with high basis weigh insulating paper, its thickness was large, during the paper folding endurance test, paper thickness direction was subjected to lateral pull force and the double-sided pressure, which accelerate fatigue destroy of the insulating paper.

\section{CONCLUSION}

Under the laboratory conditions, the thermal aging process of the insulating paper was simulated. The result showed that the thermal aging could rapidly decrease the DP, tensile strength and paper folding endurance of the insulating paper, resulting in aging degradation of the insulating paper and lowering the service life. The retention rate of the paper folding endurance was about $10 \%$ of the base paper, and the retention rate of the tensile strength was about $70 \%$ of the base paper. Compared to the tensile strength, the connection between the fibers has a greater impact on the paper folding endurance of the insulating paper. Therefore, paper folding endurance was a more realistic and efficient method to characterize the thermal aging degree of the insulating paper.

\section{REFERENCES}

[1] Bouslimi, Taheri, Fofana, et al. Influence of Oil-paper Conditions on the Static Electrification Phenomena of Transformer Oils[J]. 2013, 39(8):1966-1973

[2] Yao Mengxi. Research on uneven thermal aging characteristics of oil immersed insulating paper [D]. Southwest Jiaotong University, 2016.

[3] Wang W, Yue C P, He D X, et al. A comparative analysis of dielectric properties of oil-paper insulation and polymer materials before and after thermal aging[J]. 2014, 57(4):738-746.

[4] Yuan L A, Shi X, Wen C, et al. Improvement on Condition Assessment Model for Oil-paper Insulation[J]. Gaodianya Jishu/high Voltage Engineering, 2013, 39(8):1974-1980. 